\title{
Hypothermia and the assessment of sick children
}

\author{
Anna Cronin de Chavez research fellow, health services researcher ${ }^{1}$, Charmaine Childs professor \\ of clinical science ${ }^{1}$, Shona Kelly reader in public health ${ }^{1}$, Angela Mary Tod professor of health \\ services research ${ }^{1}$, Derek Burke medical director, consultant in paediatric emergency medicine ${ }^{2}$
}

${ }^{1}$ Centre for Health and Social Care Research (CHSCR), Sheffield Hallam University, Sheffield S10 2BP, UK; ${ }^{2}$ Sheffield Children's NHS Foundation Trust, Sheffield, UK

Although it is gratifying to see updates to the National Institute for Health and Care Excellence (NICE) clinical guideline on feverish illness in children, ${ }^{1}$ we would like to redress the balance for concern about altered thermoregulation in sick children. Fever is a cardinal sign of inflammation, infection, and trauma, but low body temperature is also a manifestation of disordered thermoregulation.

The NICE guideline focuses on febrile illness, giving a clear message about the value of different degrees of fever in the assessment of risk of serious illness, particularly in infants below 3 months of age. On the spectrum of thermoregulatory disturbance associated with disease and life threatening illness, both high fever and below "normal" temperature are seen in clinical practice. Below normal body temperature is mostly seen in severe sepsis and septic shock and is associated with a higher mortality than fever. ${ }^{2-4}$

A recent (unpublished) audit of body temperature readings in 23954 children admitted to an emergency department (Sheffield Children's NHS Foundation Trust) found that $21 \%$ presented with temperature $>37.6^{\circ} \mathrm{C}$ but $12 \%$ had a temperature $<36.0^{\circ} \mathrm{C}$. Other NICE guidance defines hypothermia as $<36.0^{\circ} \mathrm{C} .^{5}$

Therefore, below normal body temperatures are not uncommon, although the lack of standard use low reading thermometers hinders studies on the epidemiology of hypothermia.

The NICE guidance refers to only one side of human thermoregulatory disturbances, so what is its remit? Is it mainly about detecting feverish illness in children or about helping healthcare professionals identify serious childhood illness? If it is the second option, low-as well as raised-body temperature should be included in the assessment of serious illness in children and in future epidemiological studies.

Competing interests: None declared.

1 Fields E, Chard J, Murphy MS, Richardson M; on behalf of the Guideline Development Group and technical team. Assessment and initial management of feverish illness in children younger than 5 years: summary of updated NICE guidance. BMJ 2013;346:f2866. (22 May.)

2 Hofer N, Müller W, Resch B. Neonates presenting with temperature symptoms: role in the diagnosis of early onset sepsis. Pediatr Int 2012;54:486-90.

3 Milner D, Wailoo M, Swift P, Fraser M. Prolonged hypothermia following respiratory syncytial viral infection in infancy. Arch Dis Child 2003:88:69-70.

4 Remick DG, Hongyan X. Hypothermia and sepsis. Front Biosci 2006;11:1006-13.

5 National Institute for Health and Clinical Excellence. Inadvertent perioperative hypothermia. 2008. www.nice.org.uk/nicemedia/live/11962/40396/40396.pdf. 